a healthy but not robust man. No external wound or ecchymosis of chest-walls; the right pleural cavity contained seventy-five ounces of dark fluid blood, with right lung collapsed to one-fourth of its normal size, firm in consistence, and containing but a small quantity of air. A transverse rent about an inch and a half long extended through the pleura pulmonalis, and for a short distance in to the substance of the lung, on the external surface of the middle lobe. The pleura costalis was uninjured, and no fracture of the ribs existed. The left lung was emphysematous in a most marked degree, the air-vesicles in its upper third being ruptured and formed into cavities as large as a hazel-nut. The bronchial tubes showed signs of subacute inflammation, and were choked with frothy mucus. The surface of the heart was coated with a recent deposit of lymph; no fluid in the pericardium. Other organs healthy.

Remarks.-Rupture of the lung is rarely met with apart from fracture of the ribs or external injury to the thoracic walls. Erichsen states that it sometimes, although seldom, occurs; but $I$ have been unable to find any reported case. The existence of homothorax in such cases is most difficult of diagnosis; the ecchymosis of the loins described by Larrey as almost pathognomonic was not present in this case, nor was there any bulging of the intercostal spaces, as might have been expected. It is undoubted that the extravasation of blood did not take place until the reaction from shock, cough, and dyspnoe set in, and brought the wounded lung into play, and that it then took place rapidly, as evinced by the pallor of countenance, approach to collapse, and sudden sinking of temperature which supervened on the second day of the injury. Although the wound in the collapsed lung appeared small, it must have been ofvery considerable extent in the inflated organ, and paracentesis would probably have induced hæmorrhage to an immediately fatal degree. In a more robust man, however, with less emphysema of the opposite lung, I presume that empyema would have resulted as a doubtful alternative.

\section{CASE OF DIFFUSE HYPERTROPHY OF THE ADIPOSE TISSUE OF THE NECK.}

\section{Bx CHARLES OLDMAN, M.B. Cantab., \&c.}

As the diffuse form of hypertrophy of the adipose tissue confined to one region of the body, and without corresponding increase in other parts, is somewhat rare, especially in young people, I may be excused bringing the following case before the notice of the profession. Before entering fully into the details of the case, it may be remarked that the subject is barely noticed by some surgeons, and not at all by others, in their works on Surgery; thereby showing that instances are not very frequent. In Holmes's "System" (vol. i., p. 519) it is ranked among the tumours, and described as generally commencing in persons about forty years of age, and slowly increasing until it attain some uncertain size, and staying thereat; generally hardly amenable to treatment, but sometimes may be cured by the long-continued taking of liquor potassæ. Fergusson alludes to the frequency with which fatty growths occur in the subcutaneous cellular tissue of the neck, but refers probably to the encapsuled growths. (Prac. Surg., 5th edit., p. 573.) Bryant, in his Manual (p. 721), deals with the subject, but chiefly in reference to the encapsuled form; and, as regards treatment, advises removal of the encapsuled if cumbersome, but non-interference with the diffused. In other works, too, either no mention is made of this form, or, if so, no distinct line of treatment is indicated. I believe that Sir Benjamin Brodie was the first to try liquor potassæ for the removal of fatty growths, and, on hearing the anecdote relating to his discovery of this, I resolved to try it in this case, with the hope that it might be as successful as with him. The following are the notes of the case.

On Dec. 27th, 1872, I was called in to see A. L-, a girl aged twelve. The history obtained from her father was as follows:- One year ago he observed her neck gradually becoming large, but, thinking it was part of a general development of fat throughout the body, he took no further notice of it until June, 1872, when her mother remarked that "her dresses required a very long band to go round the neck." Still thinking that it was not very serious, he took no particular notice until the end of the year, when he saw that it was becoming very much larger, and that she appeared to breathe badly. This determined him to have advice.

On looking at the neck it was evident that the sides bulged out a good deal, more especially just below the also of the thyroid gland, and narrowing towards the clavicle below and the larynx above. The enlargement was greater on the right side than the left. Neither heat, redness, nor tenderness on pressure indicated any inflammatory mischief, nor was there movement of the swelling during the act of deglutition, suggestive of "goitre," it being possible to define the gland in its normal condition. The swelling was smooth, even, painless, and soft to the touch, extending across the sterno-mastoid muscles on each side, occluding them from view even when put in action, thereby ercluding any idea of glandular enlargement, but pointing solely to the adipose tissue as being the seat of the affection-a true hypertrophy. By pressure the growth interfered somewhat with respiration, and talking quickly or running caused her to make a crowing noise resembling laryngismus stridulus. In June, the tumour measured $13 \frac{1}{2}$ in. in circumference at the lowest part, the band of an old dress being the means of measurement, and on Dec. 27 th $15 \frac{1}{8}$ in. at the middle of the neck over the thyroid gland, neither measurements being made where the swelling was most prominent.

As the swelling was rapidly increasing, the difficulty of respiration becoming aggravated, and there appeared no probability of its even becoming stationary, the question arose, how was it to be stopped? I first ordered the iodide of mercury ointment to be rubbed in night and morning on each side of the neck, and iodide of potassium to be taken internally; afterwards the vapour of iodine in the room the patient slept in, and the administration of the syrup of iodide of iron. After six weeks, although no diminution was detected, yet there was no increase, the iodine evidently controlling the growth. A galvanic chain was now worn round the neck, but as this made the skin tender and caused a herpetic eruption to appear, it was discontinued. On the 13th February the patient commenced to take the liquor potassæ in fifteen-minim doses three times a day. The result was most marked. On the 17 th a diminution was perceptible, and on the $23 \mathrm{rd}$ the swelling measured only 14 in. in circumference, it having been reduced $1 \frac{1}{8}$ in. in ten days. After this date the diminution became more gradual and less noticeable, but on March 13 th, one month after commencing the liq. potassæ, it measured only $13 \frac{1}{2}$ in. About this period the dose was increased from fifteen to twenty minims, and on April 13th the measurement was $12 \frac{1}{2}$ in. round the thyroid gland and $13 \mathrm{in.}$ round the thickest part, having been reduced $25 \mathrm{~s}$. in two months. At my request the patient's father obtained measurements from six other girls, whose ages varied from thirteen to fourteen years, so as to obtain an average, the result being $11 \frac{1}{2}$ in.; but two of them, aged respectively thirteen and fourteen years, measured $12 \mathrm{in.}$ The measurements were all carefully made, with particular instructions as to their being taken in the same part of the neck in each case-namely, just below the thyroid gland. The patient's neck is so much reduced in size as not to call forth remarks about its being larger than natural. The medicine has now (April 20th) been discontinued for a time, but the swelling is still undergoing diminution.

Spalding.

Poisonous Effects of Tetramethyl of Ammonium. - At a late sitting of the Society of Biology of Paris, M. Rabuteau made some valuable remarks on the polsonous effects of the above salts, as illustrated by his experiment on animals. For instance, one-sixth of a grain of the tetramethyl kills a frog in less than five minutes. It is a muscular poison; the muscles of the heart itself are no longer excitable by electricity ten minutes after death. The iodide of tetramethyl is also a muscular poison of the same sort, less soluble, but quite as dangerous. M. Rabuteau purposes to continue his experiments with all the compounds belonging to the series. As ten grains of the tetramethyl kill a dog in a few hours, it would be prudent to take only a very small quantity in experiments on himself. Dr. Rabuteau has tried one-third of a grain. 